\title{
Adrenergic Innervation of the Mesenteric Arteries in Wistar-Kyoto Rats, Spontaneously Hypertensive Rats and Rats Treated with Monosodium Glutamate.
}

\author{
Yoshihisa KAwASE \\ Department of Pathology, Atomic Disease Institute, \\ Nagasaki University School of Medicine
}

Received for publication, February 18, 1988

\begin{abstract}
SUMMARY : The adrenergic innervation of the mesenteric arteries in WistarKyoto rats, spontaneously hypertensive rats (SHR) and rats neonatally treated with monosodium glutamate (MSG rats) was examined by using glyoxylic acid fluorescence histochemistry with quantitative analysis, by assaying tissue catecholamines with high performance liquid chromatography, and partly by electron microscopy. In the mesenteric arteries of SHR, fluorescence histochemistry study revealed that the plexus density of fluorescent nerve fibers was significantly higher, and tissue norepinephrine was increased as compared to control WKY. On the contrary, in the mesenteric arteries of MSG rats, the plexus density was reduced, through no significant difference was observed in catecholamine contents. Electron microscopic examination revealed that many axon bundles were adjacent to the external elastic lamina, and that occasionally the basement membranes of axon and smooth muscle cell were fused together for an at least $130 \mathrm{~nm}$ neuromuscular distance. The present study suggests that the adrenergic nerves of the mesenteric artery of SHR have an increase in activity and that those of MSG rats may be accompanied by a reduction in the sympathetic nerve activity.
\end{abstract}

\section{INTRODUCTION}

Not a few of diseases whose causes are unknown are now supposed to be developed due to autonomic nervous abnormalities. Autonomic nervous alterations are noteworthy not only in pathogenesis, but also in mechanisms of exacerbations induced by physical and mental stress. But little work has been done to breed experimental animals to be appropriate models of autonomic nervous abnormalities.

The present study is designed to analyse quantitatively the density of adrenergic innervation of the mesenteric artery, using three groups : Wistar-Kyoto rats (WKY), spontaneously hypertensive rats (SHR) and rats treated with monosodium-L-glutamate (MSG rats). Usefulness of these rats as models for study of autonomic nervous abnormalities is discussed.

\section{MATERIALS AND METHODS}

SHR and age-matched WKY were obtained from Charles River Japan Inc. and MSG rats were injected subcutaneously with monosodiumL-glutamate (MSG) at a dosage of $3 \mathrm{mg} / \mathrm{g}$ body weight daily for three days following birth and $4 \mathrm{mg} / \mathrm{g}$ on $5,7,9$ days of age. Thus the animals were divided into three experimental groups: WKY, SHR and MSG rats. Rats were housed to mate in colony cages under the 
conditions of controlled temperature $\left(24 \pm 2^{\circ} \mathrm{C}\right)$, humidity $55 \pm 2 \%$ ) and of artifitial light from 8 a.m. to 6 p.m. each day. Rats fed chow and tap water available ad libitum.

The mean blood pressure was measured with an indirect tail-cuff method (autonomic blood pressure recorder UR-1000 type, Ueda Manufactory) each four weeks after prewarming to $37^{\circ} \mathrm{C}$ for ten minutes. The animals were weighed and their nasoanal lengths were measured regularly. The Lee index which reflects a degree of obesity was calculated as $1000 \times{ }^{3}$ body weight $(\mathrm{g}) /$ nasoanal length $(\mathrm{cm})$. Immediately after stunned and decapitated at the ages of $4,12,24$, and 36 weeks, the mesenterium was removed and then mesenteric arteries were examined as follows.

\section{Fluorescence Histochemistry :}

The adrenergic nerve fibers were demonstrated using glyoxylic acid fluorescence histochemistry ${ }^{1,4,15)}$. Immediately after removal, the mesenterium was incubated in $2 \%$ glyoxylic acid solution (0.1 M phosphate buffer, pH 7.0, 20\% sucrose) for 30 minutes at room temperature. During immersion the mesenteric arteries were cleared from surrounding excess fat and connective tissue using surgical microscope, under approximately uniform conditions of stretch on glass slides. The stretch preparations were allowed to dry at room temperature for $10 \mathrm{~min}$ utes, incubated at $100{ }^{\circ} \mathrm{C}$ for 4 minutes, and mounted in Entellan-xylol solution. Catecholamine histofluorescence was observed using a fluorescence microscope (Olympus BH2-RFK) and at least two arbitrary fields per each specimen were photographed on color reversal film. Fluorescent fibers were traced at a final magnification of $\times 500$, and adrenergic plexus density $\left(\mathrm{mm}^{-1}\right)$ : the ratio of nerve fiber length to surface area were calibrated using quantitative image analysis system (COSMOZONE 98, Nikon Inc.).

\section{Electron Microscopy :}

For transmission electron microscopic samples, mesenteric arteries were trimmed of adherent fat and connective tissue carefully and fixed in the phosphate buffered solution ( $\mathrm{pH} 7.4$ ) mixed with $4 \%$ formaldehyde and $1 \%$ glutaraldehyde for 24 hours at $4{ }^{\circ} \mathrm{C}$.
The specimens were post-fixed in $1 \% \mathrm{OsO}_{4}$, serially dehydrated in ethanol, embbeded in Poly/Bed 812 and then sectioned on an ultramicrotome. The ultrathin sections were stained with uranyl acetate and lead citrate, and observed using JEOL 100B and JEM 1200EX electron microscopes.

For scanning electron microscopic samples, mesenteric arteries were dissected out and incubated in trypsin solution (DIFCO $; 2.5 \mathrm{mg} / \mathrm{ml}$ in phosphate buffer, $\mathrm{pH} 7.0$ ) for 30 minutes, then fixed in $3 \%$ phosphate buffered glutaraldehyde, and immersed in a solution of $2 \%$ tannic acid in glutaraldehyde for four hours. The specimens post-fixed in $1 \% \mathrm{OsO}_{4}$ for four hours were dehydrated through graded ethanol, immersed in isoamyl acetate, critical point dried, coated with gold, and then observed with JEOL JSM $35 \mathrm{C}$ scanning electron microscope.

\section{Assay of Catecholamines :}

The mesenteric arteries were partly examined for the determination of tissue catecholamine levels using high performance liquid chromatography with electrochemical detection (HPLCECD ) according to the method described by Maruyama et $a l .{ }^{16)}$.

It is necessary to convert tissue catecholamine levels of vessels on the basis of the outer surface area / tissue weight ratio, because sympathetic nerves are not distributed throughout entire layers of the vessel, but confined to the adventitial side of the media. The superior mesenteric arteries in rats at the age of 24 weeks were obtained $9 \mathrm{~mm}$ at the same portion, weighed, devided into three specimens, fixed in $10 \%$ formaline, and embedded in paraffin. Cross sections $3 \mu$ thick were stained with hematoxylineosin and outer lengths of the media were analysed morphometrically by using AMS image analysis system (Leitz, West Germany). According to the outer surface area/tissue weight ratios calculated from the data of weights of $9 \mathrm{~mm}$ artery and outer lengths, catecholamine levels of SHR and MSG rats were converted.

Analysis of Student's $t$-test was used for statistical comparison of three experimental groups.

\section{RESULTS}

SHR showed significantly high blood pressure values as compared to control WKY after the 


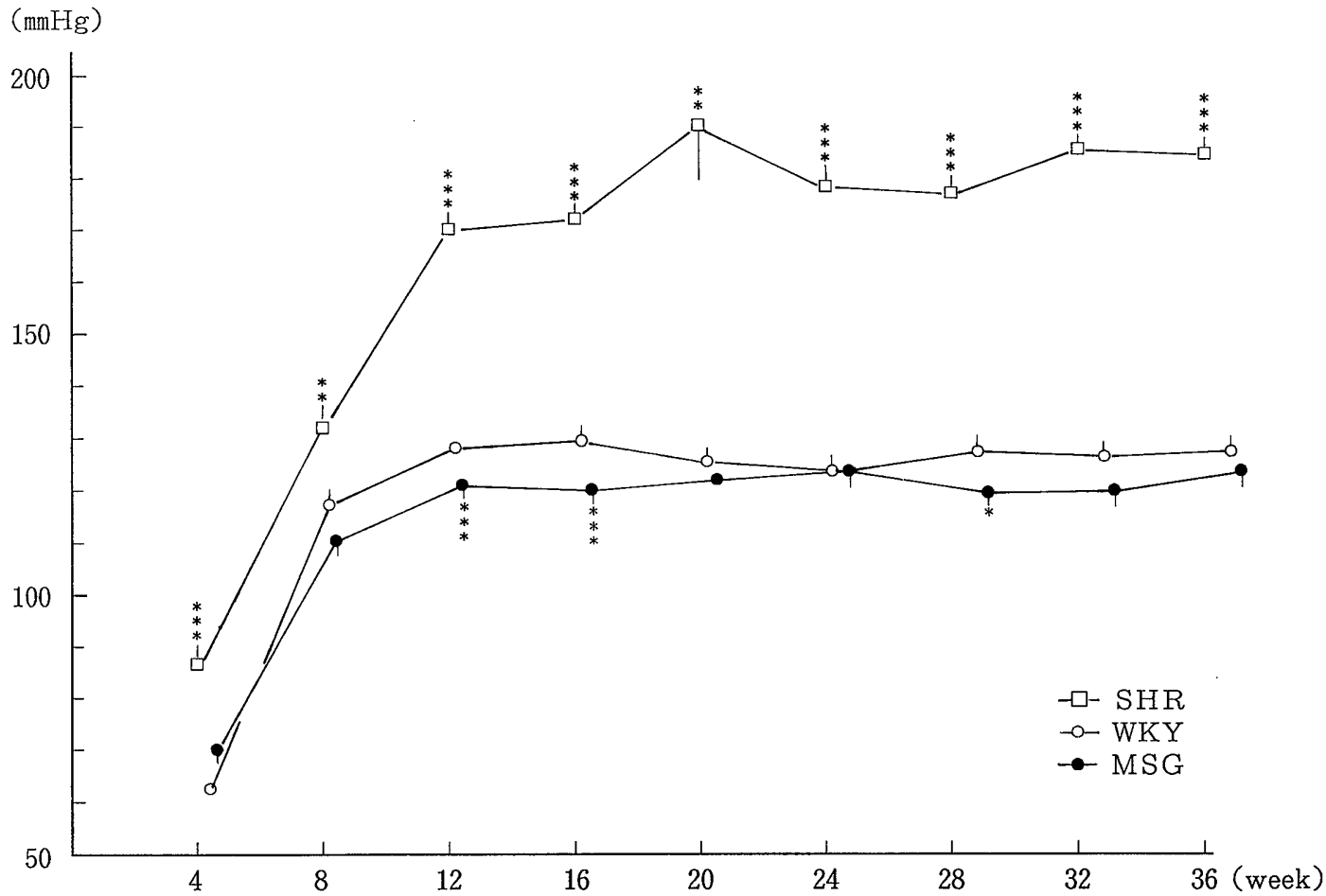

Fig. 1. Age-related changes of blood pressure. (Mean $\pm \mathrm{SE}$ )

$$
* \mathrm{p}<0.05, \quad * * \mathrm{p}<0.01, \quad * * * \mathrm{p}<0.001 \text { vs. WKY }
$$

age of four weeks. On the contorary MSG rats showed lower than WKY (Fig. 1). The body weights of SHR were higher than WKY's and no consistent difference between MSG rats and WKY was observed. As determined by the Lee index, however, MSG rats as well as SHR were significantly more obese than WKY (Table 1). MSG rats particularly exhibited marked obesity and shorter bod-length (Fig. 2), and in addition well-developed epididymal adipose tissue on autopsy.

Fluorescence Histochemistry :

Table 2 summarizes the results of a quantitative analysis of fluorescence histochemistry. Mesenteric arteries were devided into two groups : arteries measuring $100-200 \mu \mathrm{m}$ in diameter and 200-300 $\mu \mathrm{m}$. Fluorescence histochemistry revealed that mesenteric arteries were encircled by a dense plexus of fluorescent, varicose nerve fibers and that mesenteric veins were covered with a sparse plexus (Fig. 3 ). The mesenteric arteries of SHR in both groups showed a significant increase of plexus density and brighter fluorescence compared with WKY after the age of four weeks. On the contrary, the mesenteric arteries of MSG rats especially in the group of $200-300 \mu \mathrm{m}$ in diameter showed a reduction in the plexus density as compared to control WKY (Fig. 4, 5).

\section{Electron Microscopy :}

Transmission electron microscopic examination revealed that many unmyelinated axon bundles well-embedded in the Schwann cell sheath were immediately adjecent to the external elastic lamina (Fig. 6). The axon contained mitochondria, thick microtubules and small granular and clear vesicles $40-70 \mathrm{~nm}$ in diameter. The former is considered to be noradrenergic. Large granular vesicles were less commonly found, which were supposed to be peptidergic (Fig. 7, 8). At the sites of close neuromuscular contacts, the basement membranes of axon and smooth muscle cell were fused together through the fenestra of the external elastic lamina 
Table 1. Comparison of body weight and Lee index

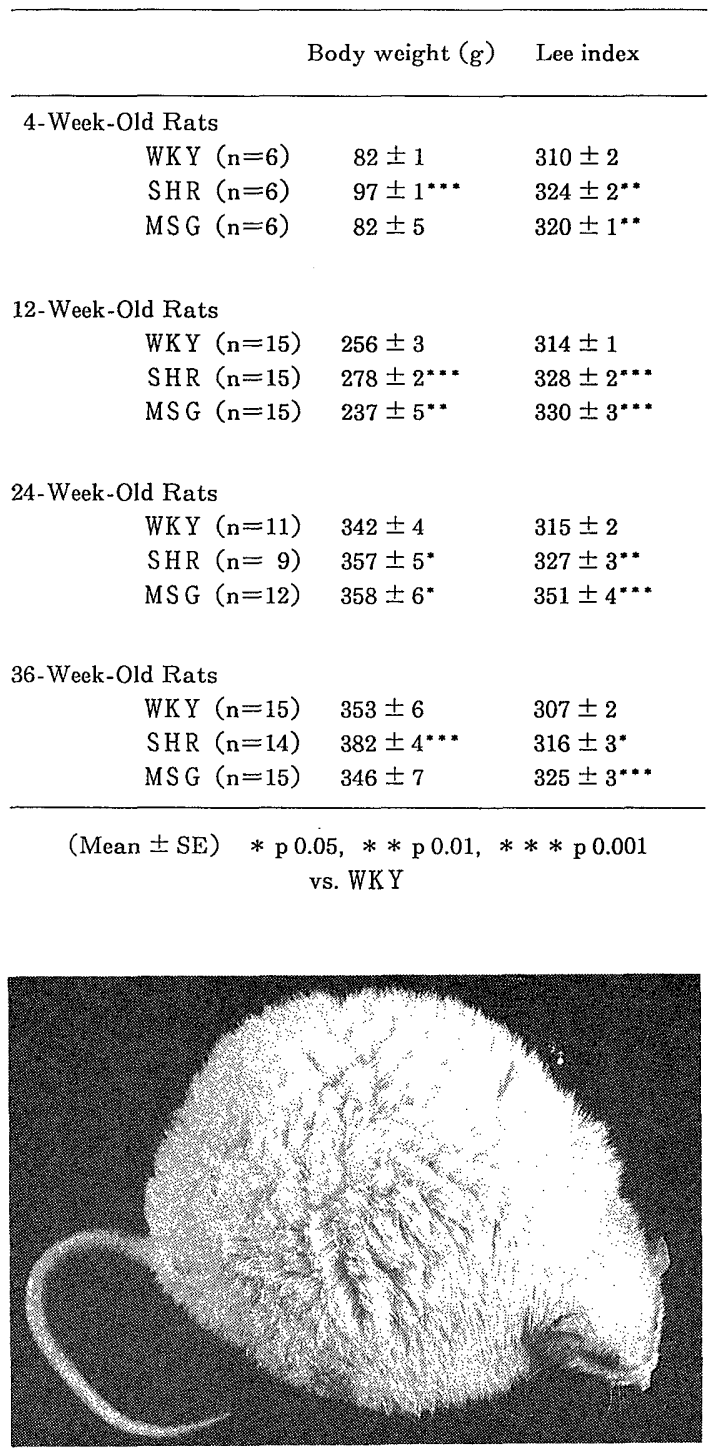

Fig. 2. MSG rat developing obesity.

(Fig. 9). Minimal neuromuscular distance was approximately $130 \mathrm{~nm}$. Scanning electron microscopic examination revealed most of perivascular nerves were deeply embedded in the adventitial fibrous connective tissue. Some dendriform or reticular nerves were sometimes found on the adventitia (Fig. 10). No qualitative difference of perivascular nerves between the three groups was observed in this study.
Table 2. Comparison of adrenergic plexus density in the mesenteric artery

\begin{tabular}{|c|c|c|}
\hline & $\begin{array}{r}\text { Adrenergic } \\
\text { (nerve fiber ler }\end{array}$ & $\begin{array}{l}\text { lexus density } \\
\text { th } / \text { area, } \mathbf{m m}^{-1} \text { ) }\end{array}$ \\
\hline \multicolumn{3}{|l|}{ 4-Week-Old Rats } \\
\hline & WKY $(n=6)$ & $109.5 \pm 1.3$ \\
\hline \multirow{2}{*}{$100-200 \mu$} & SHR $(n=6)$ & $122.4 \pm 1.5^{* * *}$ \\
\hline & MSG $(n=6)$ & $105.3 \pm 1.1^{*}$ \\
\hline \multicolumn{3}{|l|}{ 12-Week-Old Rats } \\
\hline & WKY $(n=7)$ & $99.0 \pm 7.9$ \\
\hline \multirow[t]{2}{*}{$100-200 \mu$} & SHR $(n=7)$ & $116.1 \pm 18.0^{* *}$ \\
\hline & $M S G(n=8)$ & $99.0 \pm 12.9$ \\
\hline \multirow{3}{*}{$200-300 \mu$} & WKY $(n=7)$ & $85.8 \pm 8.9$ \\
\hline & SHR $(n=7)$ & $111.8 \pm 18.7^{* *}$ \\
\hline & MSG $(n=8)$ & $79.2 \pm 6.2^{*}$ \\
\hline \multicolumn{3}{|l|}{ 36-Week-Old Rats } \\
\hline & WKY $(n=5)$ & $94.6 \pm 7.1$ \\
\hline \multirow[t]{2}{*}{$100-200 \mu$} & $\operatorname{SHR}(n=5)$ & $132.9 \pm 11.0^{*} \cdots$ \\
\hline & $M S G(n=5)$ & $88.4 \pm 6.8^{*}$ \\
\hline \multirow{3}{*}{$200-300 \mu$} & WKY $(n=5)$ & $92.0 \pm 5.6$ \\
\hline & SHR $(n=5)$ & $135.3 \pm 5.9^{* * *}$ \\
\hline & MSG $(n=5)$ & $82.6 \pm 5.4^{* * *}$ \\
\hline
\end{tabular}

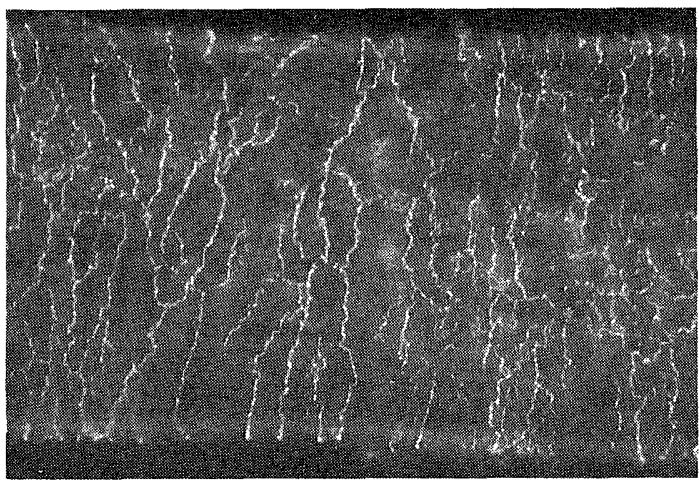

Fig. 3. Catecholamine histofluorescence of a mesenteric vein. WKY. $\times 135$.

\section{Catecholamine Contents :}

The weight and outer length values of the mesenteric arteries in SHR were greater than in WKY. Those in MSG rats, however, were significantly smaller than WKY. The ratios of outer surface area to tissue weight of mesenteric arteries were $0.96,1.23$, and 1.00 in SHR, MSG rats, and WKY respectively (Table 3 ). The catecholamine levels corrected 


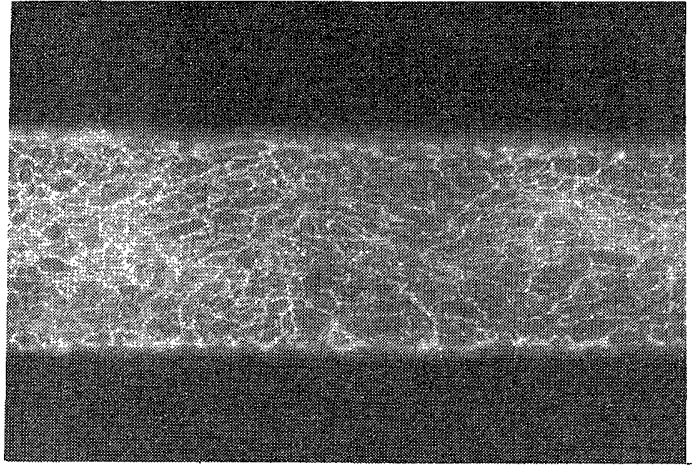

SHR

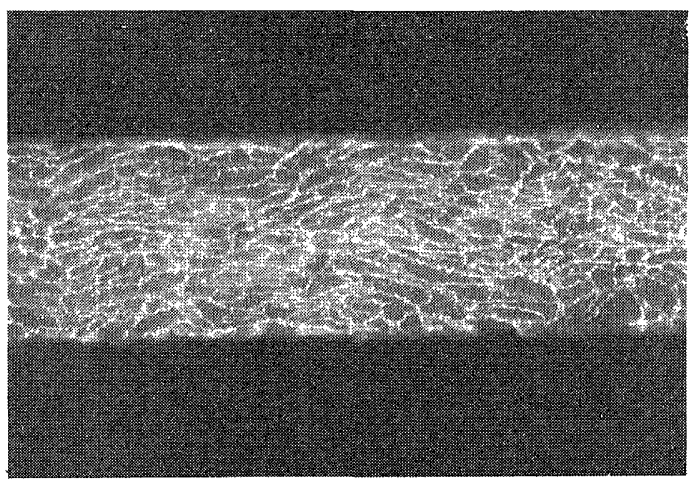

WKY

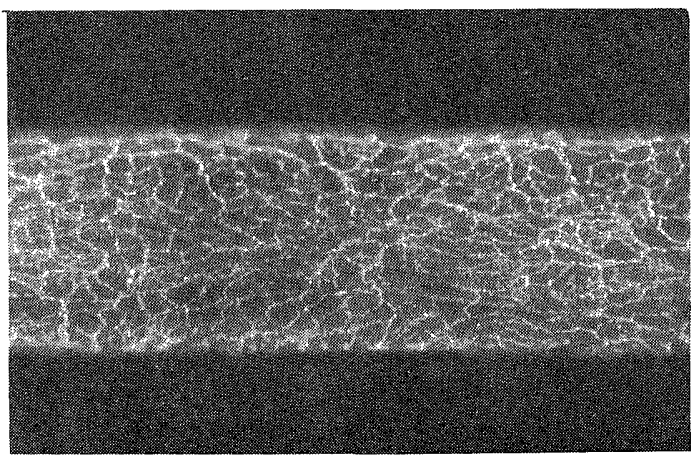

$\mathrm{MSG}$

Fig. 4. Catecholamine histofluorescence of mesenteric arteries measuring 100 $200 \mu \mathrm{m}$ in diameter in 12 -week-old rat. $\times 135$.

on the basis of these ratios are summarized in Table 4. The norepinephrine levels of SHR showed an age-dependent increase and significantly higher than those of WKY. No signifi- cant difference between WKY and MSG rats was found in neither norepinephrine nor dopamine. It was impossible to analyse statistically epinephrine contents because of extremely low levels.

\section{DISCUSSION}

Окамото et $a l .{ }^{18)}$ have developed a colony of spontaneously hypertensive Wistar rats (SHR) with a $100 \%$ incidence of spontaneously occuring hypertension in 1963. SHR have become the best model as essential hypertension, widely used by many investigators. A considerable amount of research has demonstrated that the abnormalities of sympathetic nerve centers in the thalamus and the brainstem playing an important role in the cardiovascular regulation contribute to the development of spontaneous hypertension ${ }^{7,8,24,25}$ ). There is, however, still room for research on abnormalities of endocrine and autonomic nervous systems in SHR. ICHJIMA $^{11)}$ described in his morphological studies of the jejunal small arteries of SHR that the adrenergic nerve terminals were significantly larger than in WKY in the prehypertensive stage. The present findings confirmed that SHR showed biochemically elevated catecholamine levels and morphologically dense innervation of the adrenergic nerves as previously described. It is therefore suggested that SHR may be useful as a model of sympathetic hyperactivity.

OLneY et al. ${ }^{19)}$ described in 1969 that subcutaneous injections of MSG during the neonatal period induced destructive lesions in the arcuate nuclei of the thalamus and resulted in such neuroendocrine disorders as hypogonadism, hypothyroidism and obesity. MSG rats are characteristic in that they develop obesity without hyperphagia and they have become a model in endocrinological, neurochemical and behavioral research $^{2,3,17}$ ). Little attention, however, has been focused on a morphological analysis of the sympathetic nervous system.

In this study a direct observation using fluorescence histochemistry demonstrated that the adrenergic nerve network in the mesenteric arteries of MSG rats was sparse as compared to WKY and SHR. These morphological findings suggest that the activity of the sympathetic 


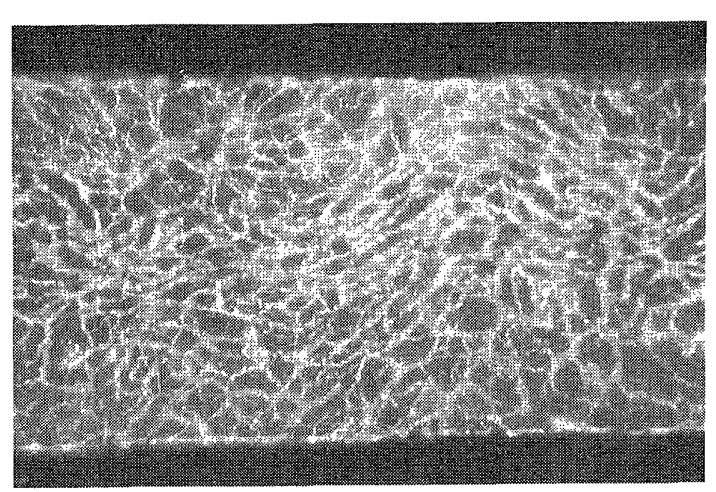

SHR

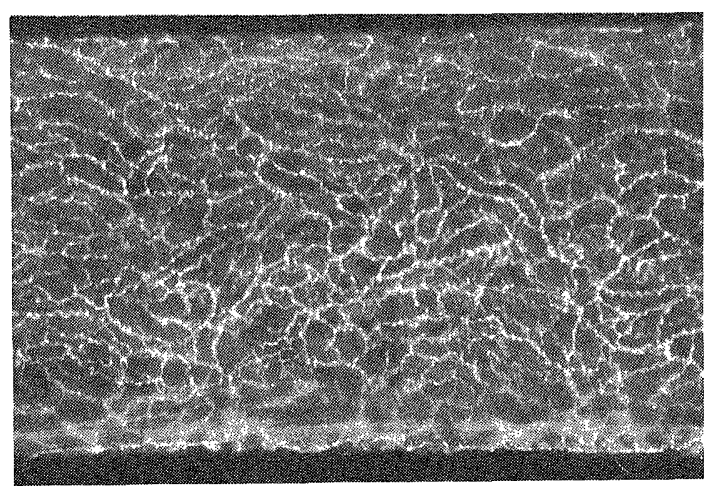

WKY

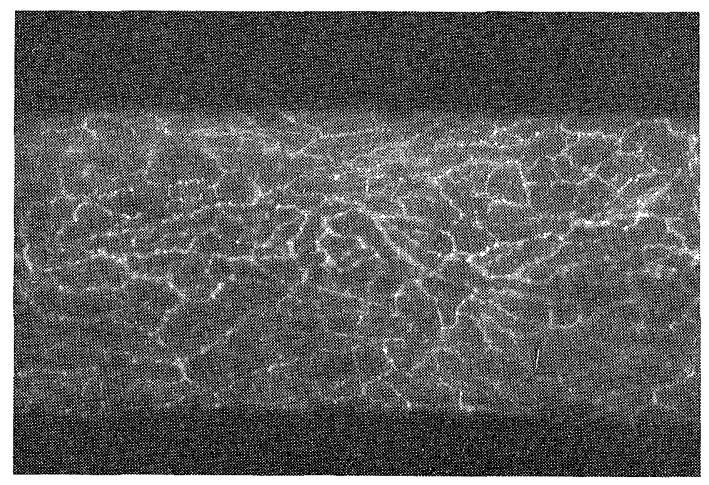

MSG

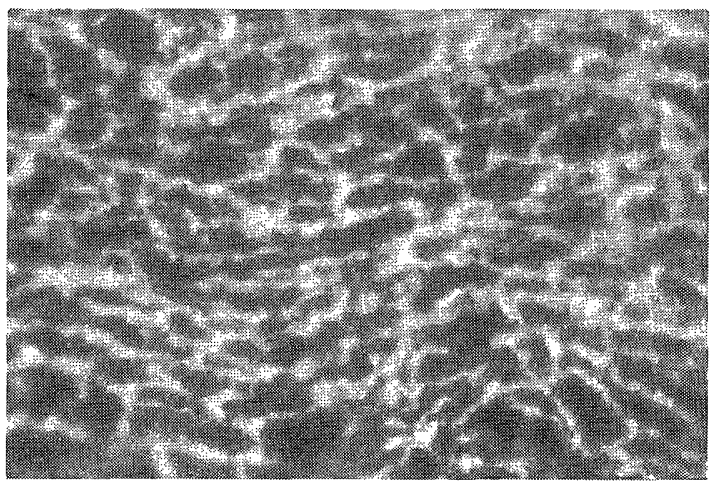

SHR

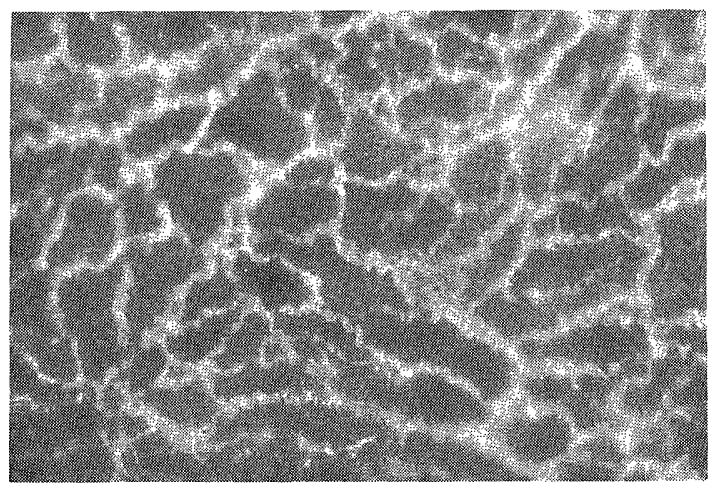

WKY

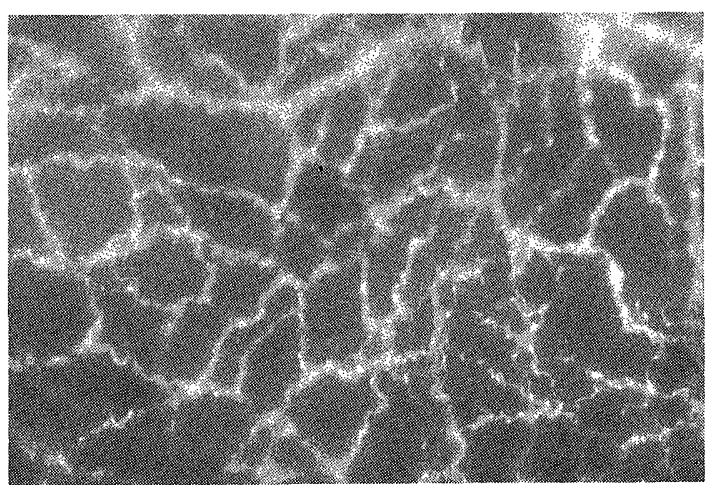

$M S G$

Fig. 5. Catecholamine histofluorescence of mesenteric arteries measuring $200-300 \mu \mathrm{m}$ in diameter in 36-week-old rats.

Left photographs $\times 135$, right $\times 270$. 


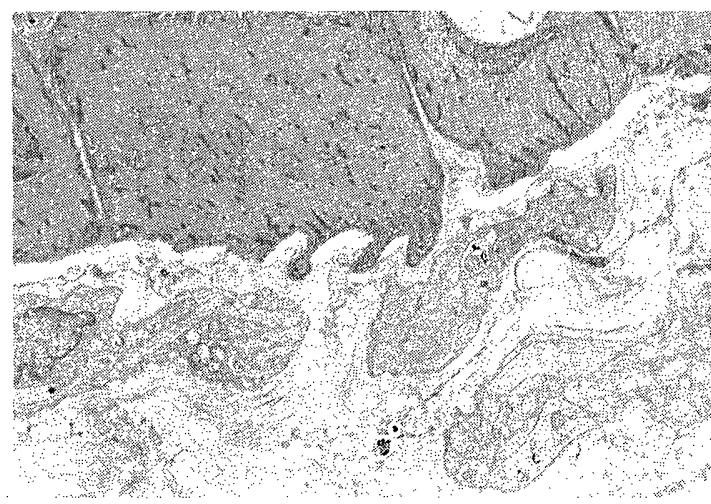

Fig. 6. Many unmyelinated axon bundles adjacent to the external elastic lamina. SHR. $\times 5000$.

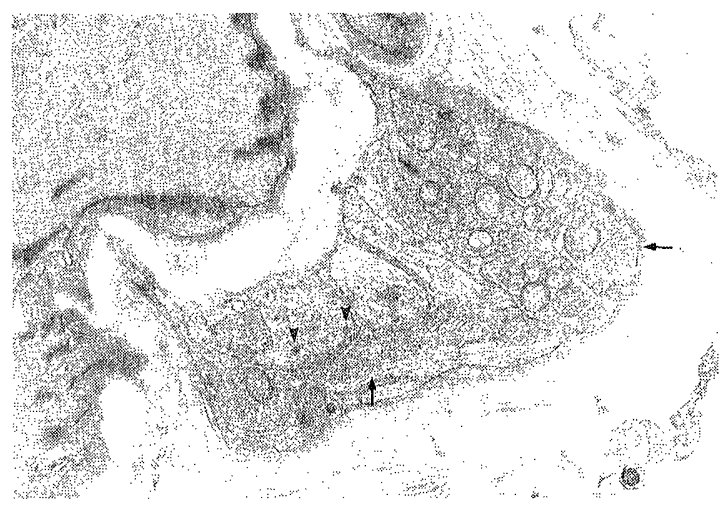

Fig. 7. Axon containing small clear vesicles (arrow) and large granular vesicles (arrowhead). SHR. $\times 12000$.

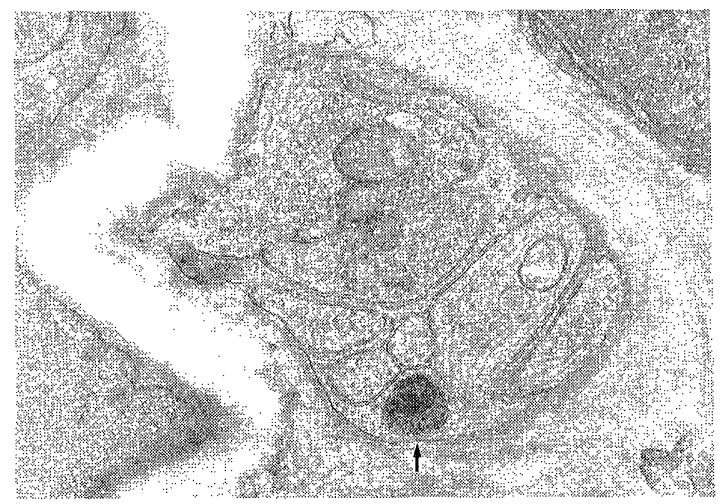

Fig. 8. Axon containing small granular vesicles (arrow) and other. SHR. $\times 21600$.

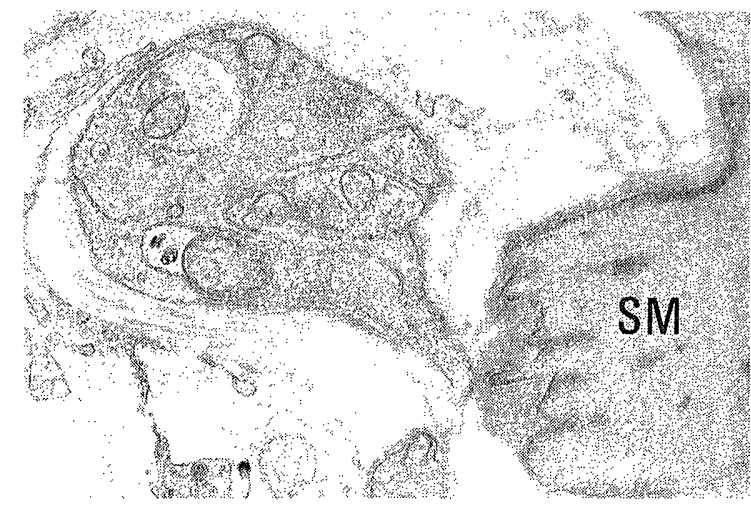

Fig. 9. Close approach of an axon bundle to smooth muscle cell (SM). SHR. $\times 20000$.

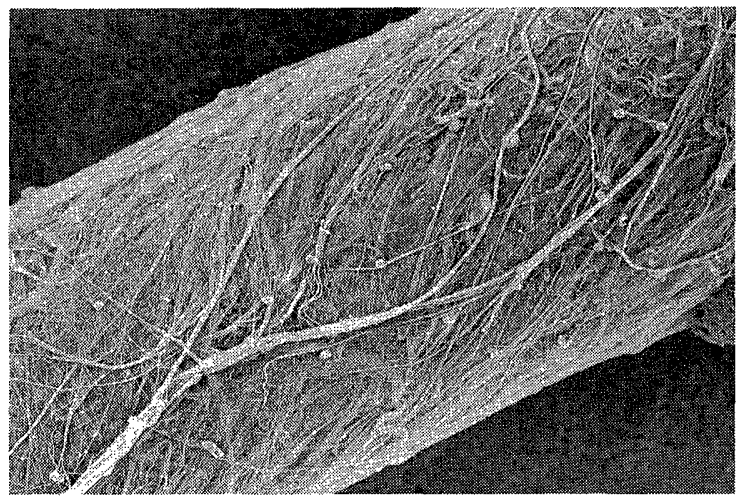

Fig. 10. Dendritic nerves in the adventitia. WKY. $\times 600$.

nerves may be reduced in MSG rats. TANAKA et $a l{ }^{21}$ ) observed that according to the time and dosage of MSG administration, the hypothalamic lesions can be included not only the arcuate nuclei but also the ventromedial nuclei and consequently induce overt obesity. BrAy and INouE et $a l . .^{5,12)}$ indicated that the increase of the vagal activity and the reduction of the activity of the sympathetic nerves following ventromedial hypothalamic (VMH) lesions may result in VMH obesity. Thus MSG-induced obesity has a close relationship with VMH obesity. Yoshma et $a l .{ }^{26,27)}$ reported that the norepinephrine turnover was reduced in mice with MSG-induced obesity. Though no signifi- 
Table 3. Comparison of weight and outer length of the mesenteric artery

\begin{tabular}{lccc}
\hline & $\begin{array}{c}\text { weight per 9mm } \\
(\mathrm{mg})\end{array}$ & $\begin{array}{c}\text { Outer length } \\
(\mathrm{mm})\end{array}$ & $\begin{array}{c}\text { Surface area per } \\
\text { weight ratio(WKY) }\end{array}$ \\
\hline WKY $(\mathrm{n}=6)$ & $3.32 \pm 0.36$ & $0.25 \pm 0.01$ & 1 \\
SHR $(\mathrm{n}=6)$ & $3.98 \pm 0.22$ & $0.29 \pm 0.01^{*}$ & 0.96 \\
MSG $(\mathrm{n}=6)$ & $2.28 \pm 0.18^{*}$ & $0.21 \pm 0.01^{* *}$ & 1.23 \\
\hline
\end{tabular}

$($ Mean $\pm \mathrm{SE}) * \mathrm{p}<0.05, * * \mathrm{p}<0.01$ vs. WKY

Table 4. Comparison of catecholamine entents in the mesenteric artery

\begin{tabular}{|c|c|c|}
\hline & $\begin{array}{l}\text { Norepinephrine } \\
\text { ( } \mu \mathrm{g} / \mathrm{g} \text { tissue) }\end{array}$ & $\begin{array}{c}\text { Dopamine } \\
(\mu \mathrm{g} / \mathrm{g} \text { tissue })\end{array}$ \\
\hline \multicolumn{3}{|l|}{ 12-Week-Old Rats } \\
\hline WKY $(n=6)$ & $4.15 \pm 0.34$ & $0.10 \pm 0.01$ \\
\hline SHR $(n=6)$ & $5.31 \pm 0.20^{*}$ & $0.15 \pm 0.01^{*}$ \\
\hline$M S G(n=6)$ & $4.48 \pm 0.38$ & $0.09 \pm 0.01$ \\
\hline \multicolumn{3}{|l|}{ 24-Week-Old Rats } \\
\hline WKY $(n=6)$ & $5.44 \pm 0.36$ & $0.39 \pm 0.08$ \\
\hline $\operatorname{SHR}(n=6)$ & $8.27 \pm 0.54^{* *}$ & $0.44 \pm 0.09$ \\
\hline$M S G(n=6)$ & $4.42 \pm 0.76$ & $0.42 \pm 0.11$ \\
\hline \multicolumn{3}{|l|}{ 36-Week-Old Rats } \\
\hline WKY $(n=5)$ & $5.52 \pm 0.55$ & $0.18 \pm 0.03$ \\
\hline SHR $(n=4)$ & $9.36 \pm 0.62^{* *}$ & $0.38 \pm 0.08$ \\
\hline$M S G(n=4)$ & $5.44 \pm 1.18$ & $0.15 \pm 0.03$ \\
\hline
\end{tabular}

$($ Mean $\pm \mathrm{SE}) * \mathrm{p} 0.05, * * \mathrm{p} 0.01$, vs. WKY

cant difference in catecholamine levels between WKY and MSG rats was found in this study, the responsiveness of arteries to norepinephrine is assumed to be reduced in MSG rats. Because it is pointed out by GLLESPE ${ }^{9)}$ that the responsiveness to norepinephrine corresponded with an innervation density of arteries and a wall thickness / lumen ratio. VAN DEN BUUSE et $a l^{23)}$ recently reported that blood pressure in SHR treated with MSG was remarkably lower than in control SHR. The present study also revealed the mesenteric arteries of MSG rats were undergrown as compared to WKY and SHR, that is in agreement with the work by ITO et al. ${ }^{13)}$ Thus MSG rats have a number of aspects contrary to SHR morphologically and functionally. SeKINE et al. ${ }^{20)}$ paid attention to this point and described an interesting investigation concerning the autonomic nervous system involved in the mechanism of stress-induced gastric ulcers, using SHR and MSG rats.

Since this study revealed that the plexus density of the adrenergic nerves in MSG rats was already lower at the age of four weeks, neuron growth factor (NGF) ${ }^{14}$ ) which is required in the development of the sympathetic nerve may be relevant to autonomic nervous alterations in MSG rats. HuL et al. ${ }^{10)}$ observed in an immunological sympathectomy using antiserum to NGF, the sympathetic neurones innervating the mesenteric arteries were more sensitive than the sympathetic neurones innervating the enteric ganglia. Thus it is necessary to disinguish two subpopulations of sympathetic neurones in the research of the mesenteric sympathetic nerves in MSG rats. It appears obvious that dense adrenergic network in the mesenteric artery plays a key role in the regulation of blood flow redistribution and gut motility $\left.{ }^{6,22}\right)$. Further studies should be done not only into morphological analysis of the mesenteric sympathetic nerves in MSG rats but also into their functions. It is speculated from this study that SHR may provide an available and valuable model of sympathetic hyperactivity and that MSG rats may be useful as a model of autonomic nervous alterations with the reduction of the sympathetic nerve activity.

\section{ACKNOWLEDGEMENT}

The author thanks Prof. Ichiro SEKINE, Deperment of Pathology, Atomic DiseaseInstitute, Dr. Nobumasa KATO, Department of Psychiatrics, Shiga Medical College, Dr. Masanori KABUTO, National Institute of Public Pollution, and Keiko AKIMOTO, Department of Pharmacology, Tokyo Women's Medical College for their constant interest and technical assistance, and Miss Mary METCALF for his editorial assistance.

\section{REFERENCES}

1) Axusson, S., Björkiund A., F alck, B., Lindvall, O. and Svensson, $\mathrm{L}-\AA$ : Glyoxylic acid condensation: a new fluorescence methood for the histochemical demonstration of biogenic monoamines. Acta. Physiol. Scand. 87: 57-62, 
2) Bakke, J. L., Lawrence, N., Bennett, J., Robinson. S. and Bowers, C. Y.: Late endocrine effects of administration monosodium glutamate to neonatal rats.

Neuroendocrinology. 26 : 220-228, 1987.

3) Berry, H. K., Butcher, R. E., Elliot, L. A. and BRUNNER, R. L. : The effect of monosodium glutamate on the early biochemical and behavioral development of the rat.

Dev. Psychobiol. 7 : 165-173, 1974.

4) Björklund, A., Lindvall, O. and Svensson, L$\AA$. : Mechanisms of fluorophor formation in the histochemical glyoxylic acid method for monoamines. Histochemie. 32 : 113-131, 1972.

5) Bray, G. A., Inoue, S. and Nishizawa, Y. : Hypothalamic obesity. The autonomic hypothesis and the lateral hypothalamus.

Diabetologia. 20 : 366-377, 1981.

6) Furness, J. B. and Marshall, J. M.: Correlation of the directly observed response of mesenteric vessels of the rat to nerve stimulation of adrenergic nerves. J. Physiol. 239:-75-88, 1974.

7) Fuxe, K., Ganten, D., Jonsson, G., Agnatr, L. F., Andersson, K., Hökrelt, T., Bolme, P., Goldstern, M., Hallman, H., Unger, T. and RASCHER, W.: Catecholamine turnover changes in hypothalamus and dorsal midline area of the caudal medulla oblongata of spontaneously hypertensive rats. Neurosci. Lett. 15 : 283288, 1979.

8) Fuxe, K., Ganten, D., Jonsson, G., Bolme, P., Agnati, L. F., Andersson, K., Goldstein, M. and HöKFELT, T. : Evidence for a selective reduction of adrenaline turnover in the dorsal midline area of the caudal medulla oblongata of young spontaneously hypertensive rats. Acta. Physiol. Scand. 107 : 397-399, 1979.

9) Gillespie, J. S. and $R_{A E}, R$. M.: The response of arteries to nerve stimulation and to noradrenaline and the relationship of this to innervation density and wall thickness. $J$. Physiol. 208 : 60-61p, 1970.

10) Hill, C. E., Hendry, I. A., NGU, M. C. and VAN HELDEN, D.: Subpopulations of sympathetic neurones differ in their sensitivity to nerve growth factor antiserum. Brain Res. 23 : 121$130,1985$.

11) ICHJIMA, K.: Morphological studies on the peripheral small arteries of spontaneously hypertensive rats. Jpn. Cir. J. 33: 785-813, 1969.

12) Inoue, S. and Bray, G. A.: Role of the autonomic nervous system in the development of ventromedial hypothalamic obesity. Brain Res. Bull. 5 : Suppl. 4, 119-125, 1980.

13) Ito, M., Kawase, Y., Shichjo, K., Sekine, I., Kaвuto, M., Акхмото, K. and Kato, N.: Morphological change of the aorta in monosodium glutamate-induced obese rats. J. Jap. Atheroscler. Soc. 15 : 1149-1151, 1987.

14) Levi-montalcini, $R$. and Calssano, P.: The nerve-growth factor. Sci. Amer. $240: 44-53$, 1979.

15) Lindvall, O. and Björlund, A.: The glyoxylic acid fluorescence histohemical method: a detailed account of the methodology for the visualization of central catecholamine neurones. Histochemistry. 39 : 97-127, 1974.

16) Maruyama, Y., Oshima, T. and NaKalima, E.: Simultaneous determination of catecholamines in rat brain by reversed-phase liquid chromatography with electrochemical detection. Life Science. 26 : 1115-1120, 1980.

17) Nemeroff, C. B., Lipton, M. A. and Kizer, J. S.: Models of neuroendocrine regulation: using of monosodium glutamate as an investigation tool. Dev. Neurosci. 1 : 102-109, 1978.

18) Окамото, K. and AokI, K.: Development of a strain of spontaneously hypertensive rats. Jpn. Cir. J. 27 : 282-293, 1963.

19) Olney, J. W.: Brain lesions, obesity, and other disturbances in mice treated with monosodium glutamate. Science. 164 :719-721, 1969.

20) Sekine, I., Shtchijo, K., Kawase, Y., Ito, M., Nishimori, I., Imamura, K., Shigemori, K., KaB uto, M., Актмото, K. and Kato, N.: Pathophysiological study of stress ulcer using SHR and monosodium-glutamate rat. Ther. Res. 6 : 937-944, 1987. (in Japanese)

21) Tanaka, K., ShImada, M., NaKao, K. and Kusu NoKr, T.: Hypothalamic lesion induced by injection of monosodium glutamate in suckling period and subsequent development of obesity. Exp. Neurol. 62 : 191-199, 1978.

22) TodD, M. E.: Development of adrenergic innervation in rat peripheral vessels : a fluorescence microscopic study. J. Anat. 131: 121$133,1980$.

23) VAN DEN BUUSe, M., Versteeg, D. H. G. and DeJonG, W.: Effects of neonatal treatment with monsodium-glutamate in spontaneously hypertensiverats. Brain Res. 19 : 135-138, 1985.

24) Y Amori, Y., Lovenberg, W. and SJoerdsma, M.: Norepinephrine metabolism in brainstem of spontaneously hypertensive rat. Science. 170 : 544-546, 
25) Yamori, Y., De yong, W., Y amabe, H., Lovenb ERG, W. and SJoerdsma, A.: Effects of L-dopa and inhibitions of decarboxylase and monoamine oxidase on brain norepinephrine levels and blood pressure in spontaneously hypertensive rats. J. Pharm. Pharmacol. $24: 690-695,1972$.

26) Yoshida, T., Nishioka, H., Nakamura, Y. and KoNDO, M.: Reduced norepinephrine turnover in mice with monosodium glutamate-induced obesity. Metabolism. 33 : 1060-1063, 1984.

27) Yoshida, T., Nishioka, H., Nakamura, Y., Kan atsuna, T. and Kondo, M.: Reduced norepinephrine turnover in brown adipose tissue of pre-obese mice treated with monosodiumL-glutamate. Life Science. 36 : 931-938, 1985. 